\title{
The Priority of Listening Comprehension over Speaking in the Language Acquisition Process
}

\author{
Fang Xu \\ Foreign Language College, Qingdao University of Science and Technology \\ PO box 502, 69 Song Ling Road, Qingdao 266061, China \\ Tel: 86-532-8190-0652Ｅ-mail: sailqd_2008@163.com
}

\begin{abstract}
By elaborating the definition of listening comprehension, the characteristic of spoken discourse, the relationship between STM and LTM and Krashen's comprehensible input, the paper puts forward the point that the priority of listening comprehension over speaking in the language acquisition process is very necessary.
\end{abstract}

Keywords: Listening comprehension, Speaking, Short-term memory, Long-term memory

\section{Introduction}

Traditionally in the field of foreign language teaching, both teachers and learners have tended to underestimate the complexity of the learning task. This tendency can be traced directly to such common sense notions as "learning by doing" and "practice makes perfect" and to the position assumed by behavioristic psychology that language learning can be described by the imitation-repetition and analogy paradigm.

Applying the new concept of learning, we can show that imitation of a foreign utterance is impossible without the use of processing devices that have been established in the human brain by prior learning. In recent years there has been an increasing interest in listening comprehension. While the audio-lingual methodology places listening first in the sequence of language skills, the listening that has taken place has been largely a listening for speaking rather than a listening for understanding.

\section{Literature Review}

\subsection{The definition of listening}

Traditionally, listening was viewed as a passive process, in which our ears were receivers into which information was poured, and all the listeners had to do was passively register the message. Today we recognize that listening is an 'active' process, and that good listeners are just as active when listening as speakers are when speaking.

Active listening is also an interpretive process. Listening used to be thought of as the exact decoding of the message. In fact, listening involves subtle interpretation. This interpretive notion has long been recognized in reading, but it has taken a long time for it to be accepted in terms of listening. Its acceptance directly affects our notions of 'correctness' - it requires an acknowledgement of the inherent variation in listeners' comprehension of what they hear, and of the importance of context and non-linguistic variables in this interpretation.

A representative definition of listening is propounded by Clark and Clark (1977: 43-44). They give both a narrow and broad definition:

"Comprehension has two common senses. In its narrow sense it denotes the mental processes by which listeners take in the sounds uttered by a speaker and use them to construct an interpretation of what they think the speaker intended to convey... Comprehension in its broader sense, however, rarely ends here, for listeners normally put the interpretations they have built to work".

\subsection{The characteristic of spoken discourse}

To understand the nature of listening processes, we need to consider some of the characteristics of spoken discourse and the special problems they pose for listeners. Spoken discourse has very different characteristics from written discourse, and these differences can add a number of dimensions to our understanding of how we process speech. For example, spoken discourse is usually instantaneous. The listener must process it "online" and there is often no chance to listen to it again.

Often, spoken discourse strikes the second-language (L2) listener as being very fast, although speech rates vary considerably. Radio monologs may contain 160 words per minute, while conversation can consist of up to 220 words per minute. The impression of faster or slower speech generally results from the amount of intraclausal pausing that speakers make use of. Unlike written discourse, spoken discourse is usually unplanned and often 
reflects the processes of construction such as hesitations, reduced forms, fillers, and repeats.

Spoken discourse has also been described as having a linear structure, compared to a hierarchical structure for written discourse. Whereas the unit of organization of written discourse is the sentence, spoken language is usually delivered one clause at a time, and longer utterances in conversation generally consist of several coordinated clauses. Most of the clauses used are simple conjuncts or adjuncts. Also, spoken texts are often context-dependent and personal, assuming shared background knowledge. Lastly, spoken texts may be spoken with many different accents, from standard or non-standard, regional, non-native, and so on.

Therefore, research has also thrown considerable light on the complexity of spoken interaction in either a first or second language. For example, Luoma (2004) cites some of the following features of spoken discourse:

Composed of idea units (conjoined short phrases and clauses)

May be planned (e.g., a lecture) or unplanned (e.g., a conversation)

Employs more vague or generic words than written language

Employs fixed phrases, fillers, and hesitation markers

Contains slips and errors reflecting online processing

Involves reciprocity (i.e., interactions are jointly constructed)

Shows variation (e.g., between formal and casual speech), reflecting speaker roles, speaking purpose, and the context

\subsection{The definition of STM and LTM}

Jack C. Richards, John Platt and Heidi Platt (2000: 283) define short-term memory (STM) as: "Short-term memory refers to that part of the memory where information which is received is stored for short periods of time while it is being analyzed and interpreted. Once the message or information in an utterance is understood the data may become part of permanent memory (or long-term memory). The utterance itself is now no longer needed and may fade from short-term memory." They also describe long-term memory (LTM) as that part of the memory system where information is stored more permanently. Information in LTM may not be stored in the same form in which it is received.

STM is transient memory. It has a limited capacity - it can only retain about seven or so unrelated chunks (a chunk is a meaningfully coded unit) once. LTM, on the contrary, is the place where more permanent information is stored. It is unlimited in capacity and holds information over a much longer interval, but it often takes a fair amount of effort to get information into it. LTM serves as a data base into which information is inserted through STM, and from which information is retrieved to be used in STM. STM plays the role of a gateway into LTM. In Call's (1985) view, memory is made up of three parts: sensory store, short-term memory and long-term memory. Information comes in from the environment through a series of sensory memory systems (iconic and auditory memory) from which it is lost unless attended. The transitory sensory store preserves information for a few hundred milliseconds; its characteristics are for the storage of visual information. Then the information goes into an intermediate STM where it has to be rehearsed before it can go into a relatively permanent LTM. Information is lost within 20-30 seconds if it is not rehearsed in STM. If the item leaves STM before a permanent LTM representation is developed, it will be lost forever. One can't retain information in STM forever since new information would always be coming in and would push out old information from the limited STM. STM can combine information from both the environment and LTM whenever a person tries to learn new information, make decisions, or solve problems. Once in STM, an item can be retained there by rehearsal. As an item is rehearsed, information about it is transferred to LTM. As soon as rehearsal of an item is brought to an end, the item soon will be displaced by a new incoming item and thus lost from STM.

\subsection{Krashen's comprehensible input}

To be useful to the learner, the input must be neither too difficult to understand nor too easy. This is conceptualized by Krashen in terms of the learner's current level, called $i$, and the level that the learner will get to next, called $i+1$. For the learner to progress rather than remain static, the input has always to be slightly beyond the level at which he or she is completely at home; the gap between the learner's $i$ and the $i+1$ that he or she needs is bridged by information drawn from the situation and from the 1earner's previous experience. 'We also use context, our knowledge of the world, our extra-linguistic competence to help us understand' (Krashen, 1982, p. 21). Comprehensible input relies on the actual language forms being incomprehensible, not the total message. This concept has indeed been called 'incomprehensible input' because the learners always have to struggle to derive meaning for the parts they do not understand rather than understanding the sentence completely (White, 1987). The 
learners progress continually from stage $i$ to stage $i+1$, along a pre-set series of stages. So the model requires a precise developmental scale on which $i$ and $i+1$ can be located. This scale invokes the natural order hypothesis: 'we acquire the rules of language in a predictable order, some rules tending to come early and some late' (Krashen, 1985, p. 1).

Krashen claims that language acquisition occurs through understanding messages or, in other words, through receiving "comprehensible input". That is, in Krashen's view, perceptive language behaviours such as listening or reading play the major role in the learning process, while everything else, including the development of speaking skills or the knowledge of grammar rules, will follow automatically as long as a sufficient amount and type of input is provided. Therefore, a student cannot be expected to produce " $i+1$ " output without learning first about the " +1 " element, that is, without receiving some sort of " $i+1$ " input.

Listening is the crucial activity. Second language learners acquire a new language by hearing it in contexts where the meaning of sentences is made plain to them. Speaking is either unnecessary or is positively harmful; active knowledge of how to use an L2 never comes from production; its only positive virtue may be that it provokes other people into speaking themselves, thus providing more listening material for the learner to work on. 'Speaking is a result of acquisition and not its cause' (Krashen, 1985, p. 2). This emphasis on listening at the expense of production distinguishes Krashen's theory from most others, for instance from 'communicative' teaching theories, which stress the importance of the learner speaking.

\section{The Priority of Listening Comprehension over Speaking}

In practical terms, listening comprehension is of paramount significance. When speaking a language, a learner can manipulate a relatively narrow range of vocabulary at his or her own pace to express an idea, but when listening to the reply he or she no longer controls the choice of vocabulary. One must be prepared to assimilate those words which are a part of the speaker's active vocabulary and must adjust to the speaker's rate of speech. In order to handle a simple conversation, an individual must have a much broader competency in listening comprehension than in speaking; this is especially the case when conversing in a foreign language with a native speaker of that language. In terms of range of lexicon and structure, the comparable capabilities might be illustrated by the areas of two concentric circles (see Figure 1.).

\section{Insert Figure 1 Here}

Moreover, in a dynamic sense, as a learner's language skill improves, we can visualize both concentric circles enlarging simultaneously with the outer (listening comprehension) circle always embracing a far greater range than the inner (speaking) circle. Emphasis on the inner circle (speaking) severely retards the expansion of the outer circle (listening comprehension). The requirement to respond orally imposes listening for speaking and results in impaired comprehension. Asher (1969, p.13) concluded that "the stress of trying to pronounce the alien utterance may retard listening fluency...The optimal strategy may be serial learning in which one achieves listening fluency just before one attempts to speak." Ley and Locascio (1972) state: "One must make association to verbal materials during learning in order that the material can be later recalled, and that some procedure such as repeatedly saying the material aloud interferes with the association process and, therefore, has a detrimental effect on learning."

Attempting to speak before listening comprehension is acquired may cause problems in speaking. The requirement to speak before one completely comprehends brings about the detrimental effect of task overload (of stress and anxiety) on language learning. High anxiety has detrimental effects on speaking: there is a tendency to force the speaker back to his or her native grammatical structure or vocabulary when the speaker becomes over-anxious (and this in turn usually leads to greater anxiety). As Gaier (1952, p.11) has expressed it: "It leads to impairment in the ability to improvise in an unstructured and/or new situation. This results in stereotyped, habitual, and familiar approaches that may be maladaptive in the situation." Speaking too soon is detrimental to both listening comprehension and speaking.

When students are tasked with production of a foreign sentence, they have to retrieve phonological, morphological, syntactical, and lexical elements stored in their memory and control their production on all these levels simultaneously and with the speed of speech output. When this task is assigned to beginning students, they are actually asked to retrieve something they have not yet stored in their memory and for which no processing strategies have been developed. Another consequence of premature oral practice, closely related to the problem of interference, is the problem of short-term memory overload. Speech is too rapid and the sentences are too long and/or complex to permit the STM to sort out the basic recurring elements. Children learning a first language are spoken to in short phrases; in many instances, one-word expressions (Broen, 1972). Short meaningful units apparently must be presented and learned so they may later be chunked into larger and larger meaningful units. Excessive exposure to a second language without meaningfulness may even be detrimental to learning the language. If the listening materials 
are very easy for the L2 learners, they can't make progress in listening practice. On the contrary, if the listening materials are more difficult for the L2 learners, the learners' STM will be overloaded and the learners will lose interest in listening acquisition. Comprehensible input is very important in the language acquisition process. It seemed to us that the building of listening comprehension through meaningful listening exercises must be as carefully researched, tried, and tested as the building of speaking ability had been attempted in the audio-lingual methodology. Most, if not all, of the foreign language material learned by the student is the type that needs to be habituated rather than conceptualized. Therefore, in the production-oriented approach, which is characteristic of the contemporary methodology of instruction, the student's short-term memory is constantly overloaded with FL (foreign language) material which he or she holds for active and instantaneous recall. Since the rate of presentation of new material is always greater than the rate of assimilation (that is, development of habitual control and automaticity of response), the short-term memory early in the course reaches a point of saturation, thereby causing considerable inhibition of the learning process. If we remove the requirement for premature speech production, the function of short-term memory will be greatly facilitated, for it will be left relatively free for new perceptual learning. Once listening comprehension is achieved, transfer to the speaking skill is very rapid.

The insights that are drawn from the above-mentioned are:

Comprehensible input is very important in the language acquisition process.

Delay of oral practice in the early stages of language learning is a key factor in reducing task overload.

Proficiency in listening comprehension is readily transferable to other language skills (including speaking and reading).

\section{Conclusion}

Therefore, listening comprehension of a foreign language should be developed as a single skill, and that development of linguistic competence is facilitated when training in oral production is not attempted until considerable fluency in aural comprehension has been developed. The second-language acquisition process can be made less strenuous and more productive by reversing the emphasis in the initial phase of instruction from intensive training in oral production to rapid development of aural comprehension.

\section{References}

Asher, J. J. (1969). The Total Physical Response Approach to Second Language Learning. The Modern Language Journal, 358, 3-17.

Broen, P. A. (1972). The Verbal Environment of the Language Learning Child. American Speech and Hearing Association Monographs, 17.

Call, M. E. (1985). Auditory Short-Term Memory, Listening Comprehension, and the Input Hypothesis. TESOL Quarterly, 19/4, 765-781.

Clark, Herbert H. \& Clark, Eve V. (1977). Psychology and Language: An Introduction to Psycholinguistics. New York: Harcourt Brace Jovanovich Inc.

Gaier, R. L. (1952). Selected Personality Variables and the Learning Process. Psychological Monographs,66 (349), 1-28.

Krashen, S. D. (1982). Principles and Practice in Second Language Acquisition. Oxford: Pergamon Press.

Krashen, S. D. (1985). The Input Hypothesis: Issues and Implications. London: Longman.

Ley, R., and Locascio, D. (1972). Associated Reaction Time in Language Acquisition. Paper Presented at the American Educational Research Association Annual Meeting, Chicago.

Luoma, Sari. (2004). Assessing Speaking. Cambridge: Cambridge University Press.

Richards, Jack C., Platt, John \& Platt, Heidi. (2000). Longman Dictionary of Language Teaching \& Applied Linguistics. Foreign Language Teaching and Research Press.

White, L. (1987). Against comprehensible input: The input hypothesis and the development of L2 competence. Applied Linguistics, 8, 95-110. 


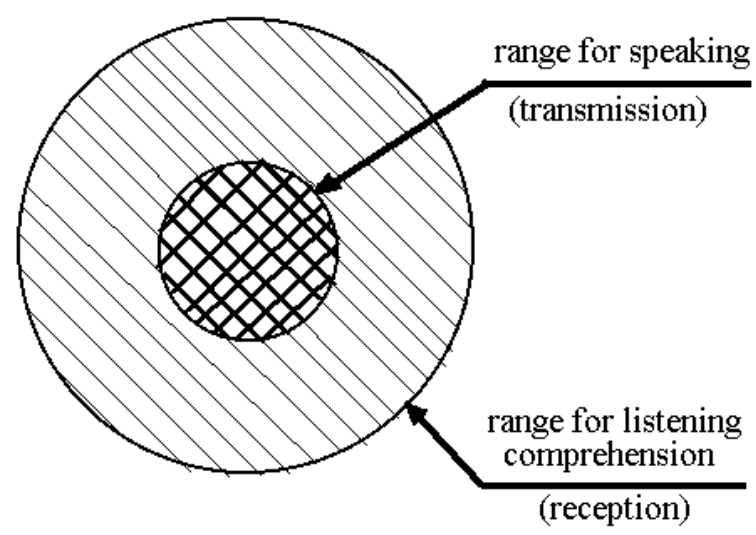

Figure 1. Normal range of receptive and expressive language ability 